\title{
Applications of Nanobiotechnology in Plant Sciences
}

\author{
Aqsa Saeed*1, Tahira ${ }^{2}$, Shaheera Qureshi ${ }^{1}$ and Waqas Manzoor Bhutta ${ }^{3}$ \\ ${ }^{1}$ Department of Plant Breeding and Genetics, University of Agriculture, Pakistan \\ ${ }^{2}$ Oilseed Research Program, Crops Sciences Institute, National Agricultural Research Centre, Pakistan \\ ${ }^{3}$ Saline Agriculture Research Centre, University of Agriculture, Pakistan \\ *Corresponding author: Aqsa Saeed, Department of Plant Breeding and Genetics, University of Agriculture, Pakistan
}

\begin{tabular}{|c|c|}
\hline ARTICLE INFO & ABSTRACT \\
\hline Received: March 23, 2021 & \multirow{3}{*}{$\begin{array}{l}\text { Nanobiotechnology is a hybrid new discipline collaborating the aspects of both } \\
\text { nanotechnology and biotechnology. Many of its applications are there in the field of } \\
\text { plant sciences which are briefly discussed in this work. Nanoparticles are its basic tools } \\
\text { which are used for the manipulation of plants. Many types of nanoparticles do exist. The } \\
\text { applications of these particles are dynamical from plant to plant. Many kinds of nano- } \\
\text { genetic modifications are made in plants which render improvements and resilience in } \\
\text { them. Agricultural developments by this nanobiotechnology are also very significant. } \\
\text { Besides all the positive developments, there also exist some harmful impacts of these } \\
\text { nanoparticles. Overall, this technology has a lot of potential and depth for the future } \\
\text { development and progress. }\end{array}$} \\
\hline Published: 㓞 April 06, 2021 & \\
\hline $\begin{array}{l}\text { itation: Aqsa Saeed, Tahira, Shaheera } \\
\text { ureshi, Waqas Manzoor B. Applications } \\
\text { f Nanobiotechnology in Plant Sciences. } \\
\text { iomed J Sci \& Tech Res 35(1)-2021. } \\
\text { JSTR. MS.ID.005632. }\end{array}$ & \\
\hline
\end{tabular}

Keywords: Abiotic Stresses; Agriculture; Nanobiotechnology; Nanoparticles

Abbreviations: TiO2: Titanium Dioxide; ZnO: Zinc Oxide; PGP: Plant Growth Profile; CAT: Chloramphenicol Acetyltransferase; SOD: Super Oxide Dismutase

\section{Introduction}

Nanotechnology is regarded as the science of manipulation of atomic and subatomic particles for developing new machinery and products which are beneficial to the human beings, whereas, biotechnology is the practical application of living things for synthesizing new products useful to humans. After the combination of these two grand approaches, we came up with a new classical discipline of science being termed as nanobiotechnology. More precisely, it can be referred as the hybrid of nanotechnology and biotechnology. The term nanobiotechnology was first coined by a biophysicist Lynn W. Jelinski, of Cornell University, USA. Nanobiotechnology is also termed as the eco-friendly technology for the synthesis of nano materials. A very wide scope of this promising new technology has been found in the field of agriculture and plant sciences. Moreover, over the last few decades nanobiotechnology has been exploited immensely in other disciplines like engineering, food technology, medical sciences and biotechnology as well. Nanoparticles which are the practical application tools of this technology, have a size between 1 to $100 \mathrm{~nm}$. All the biological entities are organized on this nanoscale and nanobiotechnology, with new insights and tools is employed to transform the biosystems of many plants.

\section{Types of Nanoparticles Used in Plants}

Nanoparticles used in this field are of the two types, i.e., metal based, and carbon based. Carbon based nanoparticles are further of two types, carbon nanotubes and fullerenes, while the metalbased nanoparticles are divided into metal oxides, quantum dots and simple metals [1]. The most widely employed metal-based nanoparticles are Titanium dioxide (TiO2), Silver, Gold, Zinc oxide ( $\mathrm{ZnO}$ ) and Copper [2]. Based on the type of nanoparticles used, they cause many physiological and morphological changes in the plants. The type, chemical composition, reactivity and most significantly the effective dose of nanoparticles are vital in this regard.

\section{Nanoparticles Utilization in Plants \\ Silicon Dioxide Nanoparticles}

It has been noted that a very low concentrations of silicon dioxide nanoparticles improved germination in some plants like 
tomato, maize etc. Along with the improvement of germination percentages, these nanoparticles also enhanced root length, root diameter and the number of lateral roots in the seedlings [3].

\section{Zinc Oxide Nanoparticles}

Many studies suggest that these nanoparticles increase the rate of development and growth in the plants like soybean, peanut, wheat etc. [4-6].

\section{Carbon Nanotubes}

These nanoparticles have distinct mechanical, thermal, electrical and chemical properties. They can penetrate easily in the cell membrane and cell wall of the plant cell making the process of nanoparticles relatively easier. Increased germination rates by using carbon nanotubes has been observed in Brassica juncea, rice, tomato and Bt cotton [7]. It is being observed that carbon nanotubes also contributes to the flowering, fruit yield, biomass and medicinal attributes of some plants [8].

\section{Gold Nanoparticles}

Relatively few studies have been performed to analyses the effects of gold nanoparticles in plants. However, these studies indicate that these nanoparticles significantly improve the seed germination rates in lettuce, cucumber, Brassica juncea, Boswellia ovalifoliolata and Gloriosa superba [9-12].

\section{Silver Nanoparticles}

A great research work has been documented on the effects of silver nanoparticles in microbial and animal cells. However, research work on plants is limited in this case. Biologically synthesized silver nanoparticles increase the seed germination and growth of Boswellia ovaliofoliolata trees [11], along with the enhancement of some biochemical attributes and plant growth profile (PGP) of maize, common bean and Brassica juncea $[13,14]$.

\section{Titanium Dioxide Nanoparticles}

These nanoparticles have been observed to increase the seed germination and length of radicle and plumule in canola [15].

\section{Nano-Genetic Manipulation of Plants}

Nanobiotechnology employs nanofibers, nano capsules and nanoparticles for the betterment of plants through gene manipulation. Nano materials are used as vehicles to carry genes and substances into the plant body which trigger gene expression and control genetic material inside the plants. Scientists are of the view that this nanobiotechnology is taking the genetic engineering of plants to a new era of atomic engineering. By utilizing this new approach of atomic engineering, scientists are now able to redesign the DNA of the seeds to incorporate desirable traits like changing yield, growth seasons and colour of the plant into it.

\section{Genetically Modified Plants through Nanobiotech- nology}

Many companies worldwide are now launching genetically modified crops with better combinations of desired traits. All these efforts are done by scientists to increase the production of the crops to feed the ever-growing population of the world. All the companies previously were employing Agrobacterium tumefaciens mediated method for this purpose or in few crops gene gun was also employed [16,17]. Although now these technologies for DNA delivery in the plant cells have become relatively common and are practiced on a large scale but scientists are of the opinion that besides DNA, the incorporation of other molecules like proteins in the cells is more tedious, difficult and challenging. The main advantage of protein delivery along with DNA into the plants is that it permits the genome editing of plants more conveniently in the desired manner. This co-delivery of DNA and proteins has been successfully experimented in tobacco, maize and onion plant tissues by using biolistic method.

\section{Nanobiotechnology and Agricultural Development}

Nanobiotechnology has played a prominent role in agricultural development mainly by the better control of plant nutrients, improved disease resistance and pesticides development for sustainable agriculture. Applications of nanobiotechnology in the form of as nano-pesticides and nano-fertilizers is discussed below.

\section{Nano-Pesticides}

Besides the wide usage of synthetic pesticides by the farmers, bio-pesticides have their own distinct status in the control of insects and pests. A new technology has been introduced in the field of bio-pesticides, that is the use of nanobiotechnology. In this regard, synthesis of non-toxic and eco-friendly nano-pesticides is of great importance. Metallic nanoparticles exhibiting relatively superior anti-pathogenic, anti-fungal and anti-bacterial qualities are being used in these nano-pesticides. But for the usage of these nano-pesticides in the field, their ecotoxicological aspects on the environment should be considered wisely as these nano pesticides also kill the soil harbouring microorganisms [18,19]. The soil microbes are mandatory for the plants as they serve many ecological and biological purposes.

\section{Nano-Fertilizers}

Nano-fertilizers are made these days which contain silica, iron and titanium dioxide, zinc and gold nano-rods. Nanoparticles of zinc oxide, iron etc. are important as they ensure the efficient uptake of nutrients by the plant. But their success depends upon many factors like plant species, susceptibility and on the size, composition and chemical properties of nano materials including their concentration used. Nano-fertilizers which are eco-friendly 
and are beneficial too for the ecosystems are more preferred than the conventional ones because the world is moving towards smart agriculture like the organic farming which protects the environment from all the hazards of chemicals [20,21].

\section{Nanobiotechnology Application for Mitigating Abiotic Stresses in Plants}

Abiotic stress affects adversely plant growth and productivity. Out of all the abiotic stresses, the two- salinity and drought are the most prevalent in all plant $[22,23]$. Realizing this fact, scientists and researchers from decades are working to find out new methodologies to overcome these stresses in plants. Employment of nanobiotechnology is another effort of the scientists in this regard. This nanobiotechnology application has gained immense upheaval nowadays because of its promising performance in this field. Plants being sessile living organisms develop in themselves the strength and defense to cope up with the harsh environmental conditions mainly by the modification of their biochemical, molecular and physiological pathways. Nanoparticles are used in this regard to regulate the activities of antioxidant enzymes like chloramphenicol acetyltransferase (CAT), super oxide dismutase
(SOD) and peroxidase which are very effective in overcoming the drought conditions [23]. Applications of nano-silicon dioxide particles on plants resulted in the increase of their chlorophyll contents, leaf fresh and dry weights, accumulation of proline and regulation of antioxidant enzymes under saline conditions.

\section{Future Generation Stress Tolerant Transgenic Plants}

In today's agriculture, abiotic stress tolerant plus transgenic plants are highly desirable on commercial scales. With this realization, the scientists are working on newer methods to achieve more milestones in this field. By means of this new method, many more species of plants can be transformed and sole reliance on Agrobacterium method for genetic transformation will be reduced as the Agrobacterium method is limited and not feasible in all plant species [22]. So, by the combination of biotechnological and nanotechnological aspects, it is possible now that many new plants can be transformed to tolerate abiotic stress in more advanced ways with improved and desired combination of agronomic traits as well [22].

\section{Negative Impacts of Nanobiotechnology on Plant Production}

Table 1: Examples of some nanoparticles applications in plants.

\begin{tabular}{|c|c|c|c|c|c|}
\hline S. No. & Nano Particles & Concentrations & Plant & $\begin{array}{c}\text { Part of Plant/ } \\
\text { Process }\end{array}$ & Reference \\
\hline 1 & Aluminium oxide & $400-4000 \mathrm{mg} / \mathrm{L}$ & Arabidopsis thaliana & Root length & Lee, et al. [25] \\
\hline 2 & Iron oxide & $0.5-0.75 \mathrm{~g} / \mathrm{L}$ & Glycine max & Yield and Quality & Sheykhbaglou, et al. [26] \\
\hline 3 & Copper oxide & $500 \mathrm{mg} / \mathrm{kg}$ & Triticum aestivum & Biomass & Dimkpa, et al. [27] \\
\hline \multirow{2}{*}{4} & \multirow{2}{*}{ Alumina } & $10 \mathrm{mg} / \mathrm{L}$ & Lemna minor & Root Length & Juhel, et al. [28] \\
\hline & & $0.3 \mathrm{~g} / \mathrm{L}$ & Lemna minor & Biomass Accumulation & Juhel, et al. [28] \\
\hline 5 & Hydroxy apatite suspension & $100-2000 \mathrm{mg} / \mathrm{L}$ & Lactuca sativa & Root Length & Wang, et al. [29] \\
\hline
\end{tabular}

Usually, the nanoparticles utilized in plants have a level of toxicity as well which is harmful for the plants to some extent but are more harmful for the microbial life or microflora existing in the soil. Nanoparticles and free radicles which usually generate toxicity, ultimately leads to DNA damage and peroxidation of lipids in plants [24]. Moreover, heavy metals have a toxicological mechanism in the form of reactive oxygen species in plants and it has been observed that if a plant is under some biotic or abiotic stress then the generation of these reactive oxygen species increases and results in necrosis and oxidative damages in plants. The production of reactive oxygen species is a very serious and dangerous effect of nanoparticles which must be overcome necessarily for the more frequent and efficient utilization of this technology in plants [2529] (Table 1).

\section{Conclusion and Future Perspectives}

Nanobiotechnology is a promising new combination of the two very important disciplines. Many new procedures are underway for more appropriate utilization of nanobiotechnology in plant sciences. The developments in nanobiotechnology are not only limited to the plants but are multi-directional also and spreading in all areas of human life. The world population is increasing rapidly by every year and the issues of global food security are becoming more significant in the developing countries. Moreover, in view of the recent problem of the climate change worldwide, there is a need for equipping the plants to cope up with all the abiotic stresses also. Scientists are hoping to utilize this nanobiotechnology more efficiently and frequently to brought new innovations in plant sciences which will result in the development of more resilient and stable plant species available for mankind in these changing climatic conditions.

The utilization of nanoparticles, particularly for tissue culturing in plants has gained immense upheaval in this science of nanobiotechnology. The main reason for this science in achieving tremendous impetus nowadays is its ability to modulate metals 
in their nano size. Although this nanobiotechnology has some negative implications in some plants as well, but this is another challenge and goal for the scientists to overcome this with better technology, procedures and strategies. So, in short, the knowledge of nanoparticles which are the basic tool of nanobiotechnology, their interaction with the environment, plant cells and other biological systems is mandatory to develop a more insight and a vast utilization of this technology.

\section{Author Contributions}

AS and T came up with the idea and wrote the manuscript while WMB and SQ critically reviewed and proofread the manuscript.

\section{Conflict of Interest}

All authors declare no conflict of interest.

\section{References}

1. Peralta Videa JR, Zhao L, Lopez Moreno ML, de la Rosa G, Hong J, et al. (2011) Nanomaterials and the environment: a review for the biennium 2008-2010. Journal of hazardous materials 186(1): 1-15.

2. Keller AA, McFerran S, Lazareva A, Suh S (2013) Global life cycle releases of engineered nanomaterials. Journal of nanoparticle research 15(6): 1692.

3. Bao Shan L, Chun Hui L, Li Jun F, Shu chun Q, Min Y (2004) Effect of TMS (nanostructured silicon dioxide) on growth of Changbai larch seedlings. Journal of Forestry research 15(2): 138-140.

4. Prasad TNVKV, Sudhakar P, Sreenivasulu Y, Latha P, Munaswamy V, et al. (2012) Effect of nanoscale zinc oxide particles on the germination, growth and yield of peanut. Journal of plant nutrition 35(6): 905-927.

5. Sedghi M, Hadi M, Toluie SG (2013) Effect of nano zinc oxide on the germination parameters of soybean seeds under drought stress. Annales of West University of Timisoara. Series of Biology 16(2): 73-78.

6. Ramesh M, Palanisamy K, Babu K, Sharma NK (2014) Effects of bulk \& nano-titanium dioxide and zinc oxide on physio-morphological changes in Triticum aestivum Linn. J Glob Biosci 3(2): 415-422.

7. Morla S, Rao CR, Chakrapani R (2011) Factors affecting seed germination and seedling growth of tomato plants cultured in vitro conditions. Journal of Chemical, Biological and Physical Sciences (JCBPS) 1(2): 328334.

8. Husen A, Siddiqi KS (2014) Carbon and fullerene nanomaterials in plant system. Journal of nanobiotechnology 12: 16.

9. Barrena R, Casals E, Colón J, Font X, Sánchez A, et al. (2009) Evaluation of the ecotoxicity of model nanoparticles. Chemosphere 75(7): 850-857.

10. Arora S, Sharma P, Kumar S, Nayan R, Khanna PK, et al. (2012) Goldnanoparticle induced enhancement in growth and seed yield of Brassica juncea. Plant growth regulation 66(3): 303-310.

11. Savithramma N, Ankanna S, Bhumi G (2012) Effect of nanoparticles on seed germination and seedling growth of Boswellia ovalifoliolata an endemic and endangered medicinal tree taxon. Nano Vision 2: 61-68.

12. Gopinath K, Gowri S, Karthika V, Arumugam A (2014) Green synthesis of gold nanoparticles from fruit extract of Terminalia arjuna, for the enhanced seed germination activity of Gloriosa superba. Journal of Nanostructure in Chemistry 4(3): 115.

13. Salama HMH (2012) Effects of silver nanoparticles in some crop plants, common bean (Phaseolus vulgaris L.) and corn (Zea mays L.). Int Res J Biotech 3(10): 190-197.

14. Sharma P, Bhatt D, Zaidi MG, Saradhi PP, Khanna PK, et al. (2012) Silver nanoparticlemediated enhancement in growth and antioxidant status of Brassica juncea. Appl Biochem Biotechnol 167(8): 2225-2233.

15. Mahmoodzadeh H, Nabavi M, Kashefi H (2013) Effect of nanoscale titanium dioxide particles on the germination and growth of canola (Brassica napus). J Ornamental Hortic Plants 3(1): 25-32.

16. Christou P, McCabe DE, Swain WF (1988) Stable transformation of soybean callus by DNA-coated gold particles. Plant Physiology 87(3): 671-674.

17. Gelvin SB (2003) Agrobacterium-mediated plant transformation: the biology behind the "gene-jockeying" tool. Microbiology and molecular biology reviews 67(1): 16-37.

18. Kah M, TJEI Hofmann (2014) Nanopesticide research: current trends and future priorities 63: 224-235.

19. Servin A, W Elmer, A Mukherjee, R De La Torre Roche, H Hamdi, et al. (2015) A review of the use of engineered nanomaterials to suppress plant disease and enhance crop yield 17: 1-21.

20. Subramanian KS, A Manikandan, M Thirunavukkarasu, CS Rahale (2015) Nano-fertilizers for balanced crop nutrition. Nanotechnologies in food and agriculture, p. 69-80.

21. Thul ST, BK Sarangi (2015) Implications of nanotechnology on plant productivity and its rhizospheric environment. Nanotechnology and plant Sciences, p. 37-53.

22. Lavania D, AK Singh, MH Siddiqui, MH Al Whaibi, A Grover (2015) Abiotic Stress Tolerant Transgenic Plants and Nanotechnology. Nanotechnology and Plant Sciences, pp. 165-181.

23. Zhao L, Lu L, Wang A, Zhang H, Huang M, et al. (2020) Nano-biotechnology in agriculture: use of nanomaterials to promote plant growth and stress tolerance. Journal of agricultural and food chemistry 68(7): 1935-1947.

24. Mwaanga Phenny (2018) Risks, Uncertainties, and Ethics of Nanotechnology in Agriculture.

25. Lee CW, Mahendra S, Zodrow K, Li D, Tsai YC, et al. (2010) Developmental phytotoxicity of metal oxide nanoparticles to Arabidopsis thaliana. Environmental Toxicology and Chemistry: An International Journal 29(3): 669-675.

26. Sheykhbaglou R, Sedghi M, Shishevan MT, Sharifi RS (2010) Effects of nano-iron oxide particles on agronomic traits of soybean. Notulae Scientia Biologicae 2(2): 112-113.

27. Dimkpa CO, McLean JE, Latta DE, Manangón E, Britt DW, et al. (2012) CuO and ZnO nanoparticles: phytotoxicity, metal speciation, and induction of oxidative stress in sand-grown wheat. Journal of Nanoparticle Research 14(9): 1-15.

28. Juhel G, Batisse E, Hugues Q Daly D, van Pelt FN, et al. (2011) Alumina nanoparticles enhance growth of Lemna minor. Aquatic toxicology 105(3-4): 328-336.

29. Wang M, Chen L, Chen S, Ma Y (2012) Alleviation of cadmium-induced root growth inhibition in crop seedlings by nanoparticles. Ecotoxicology and environmental safety 79: 48-54. 


\section{ISSN: 2574-1241}

DOI: 10.26717/BJSTR.2021.35.005632

Aqsa Saeed. Biomed J Sci \& Tech Res

(C) (i) This work is licensed under Creative BY Commons Attribution 4.0 License

Submission Link: https://biomedres.us/submit-manuscript.php

\begin{tabular}{ll} 
BIOMEDICAL & \multicolumn{1}{c}{ Assets of Publishing with us } \\
RESEARCHES & - Global archiving of articles \\
- Immediate, unrestricted online access & - Rigorous Peer Review Process \\
& - Authors Retain Copyrights \\
\end{tabular}

